\title{
Power Flow Study and Voltage Stability Analysis for Radial System with Distributed Generation
}

\author{
Mostafa H. Mostafa \\ Cairo University
}

\author{
Mostafa A. Elshahed \\ Cairo University
}

\author{
Magdy M. Elmarsfawy \\ Cairo University
}

\begin{abstract}
The voltage instability phenomena occur in both transmission systems and distribution systems. The weakening of voltage stability level will limit the growth of load served by distribution companies. Voltage instability in power distribution systems could lead to voltage collapse and thus power blackouts. The integration of distributed generation (DG) in the distribution system has increased to high penetration levels. The ultimate goal of this paper is studying the impact of DG units under varied penetration level on some issues, such as voltage stability, voltage profile, power flow and PV curves for each bus. This paper analyzes and discusses the performance of static voltage stability of 15 buses a practical distribution system in the Kumamoto area in Japan by using Fast Voltage Stability Index FVSI and varying the load ability with varied DG penetrations. In this paper, two types of DG sources are used in distribution systems wind turbine and photovoltaic.
\end{abstract}

\section{Keywords}

Voltage Stability, Distributed Generation, Loadability, Static Voltage Stability, Power Flow, Wind Turbine and Photovoltaic.

\section{INTRODUCTION}

The integration of distributed generation (DG) to power system networks has quickly increased from renewableenergy sources [1]. This increase can be clarified by elements such as environmental concerns, the growth of electricity businesses, the advance of technologies, goals related to emission reduction, energy independence, and improved infrastructure reliability [2], [3].

The integration of DG units had an impact on the voltage profile, power flow, power quality, stability, reliability, protection, emission of pollutants and line losses [3]-[5]. Since DG units have a small size compared to central power plants, the impact is slight if the penetration level is low (1\%$5 \%$ ). However, if the penetration level of DG increases to the level of 20\%-30\%, the impact of DG units will be deep [2]. The increase of DG penetration will change the energy structure of the grid; affect the grid voltage, power quality and the operational planning [6]-[8], among which voltage stability problem is an important aspect. The voltage stability is concerned with the capability of a power system to sustain suitable voltages at all nodes in the system under normal condition and after being subject to a disturbance [9]. A power system has a state of voltage instability when a disturbance causes a progressive and un- controllable decrease in voltage level. During the last periods, the voltage stability problem is more important due to a number of stability accidents that happened in some countries. Some well- known examples of voltage stability incidents were reported in France, Belgium, Sweden, Germany, Brazilian, Japan and USA [9]-[11].
The voltage instability incidents occur in both transmission systems and distribution systems [12], [13]. It has not been new to power system working engineers and research.

The operation conditions of distribution networks are closer to the voltage stability limits due to grow load demands in distribution networks. The weakening of voltage stability level in power systems is one of the main reasons, which limited the growth of load served by distribution companies \& one of the major concerns in power system planning and operation [14], [15].

The research on the voltage stability can be classified into a static and dynamic analysis [16]. The static voltage stability analysis is based on power flow calculations [9]. Static voltage stability of the grid Combining DG mostly depends on the capacity (namely penetration), type (including different control methods) and the integrating location of DG [17]-[20].

In this paper DGs connected to distribution networks are potential to improve the system voltage stability. It uses the static analysis to discuss the impacts of DGs on the voltage stability in distribution systems. Furthermore, it studies the impact of DG on voltage profile, power flow and PV curves for each bus. In this paper, two types of DG sources are used in distribution systems wind turbine and photovoltaic.

\section{STATIC VOLTAGE STABILITY INDEX}

The condition of voltage stability in a power system can be characterized using of voltage stability indices. These indices can disclose the critical bus of a power system or the stability of each line connected between two buses in an interconnected network or evaluate the voltage stability margins of a system [21]. The indices used to examine the system stabilities are briefly described in this section.

\subsection{Fast voltage stability index FVSI}

Fast voltage stability index abbreviated by FVSI referred to a line is formulated in this study as the measuring instrument in predicting the voltage stability condition in the system. Figure 1 illustrates a single line of an interconnected network. The FVSI proposed by I. Musirin et al. [22] is based on a concept of power flow through a single line. Equation (1) uses to calculate FVSI.

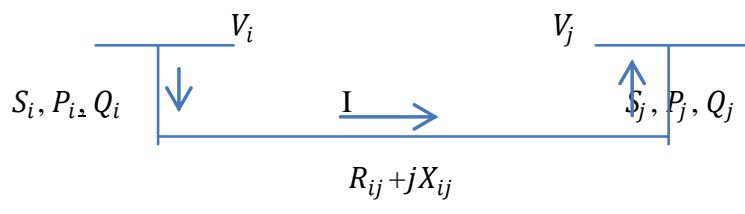

Fig 1: Typical on line diagram of transmission line

$$
\mathrm{FVSI}_{\mathrm{ij}}=\frac{4 \mathrm{Z}^{2} \mathrm{Q}_{\mathrm{i}}}{\mathrm{V}_{\mathrm{i}}^{2} \mathrm{X}_{\mathrm{ij}}}
$$

Where

$\mathrm{Z}$ is the line impedance

$X_{i j}$ is the line reactance 
$Q_{j}$ is the reactive power flow at the receiving end

$V_{i}$ is the sending end voltage

The line that gives index value closest to 1 will be the most critical line and may lead to the whole system instability. To rightly a secure condition the value of FVSI should be below 1.00 .

\subsection{P-V Curves}

The P-V curves are the most-used method of forecasting voltage security. They are used to determine the loading margin of a power system. The power system load is gradually increased and, at each increment, is necessary recomputed power flows until the nose of the PV curve is reached [23].

The P-V curve is obtained by applying a continuous power flow method [24]. The critical point $\lambda \max$ in the P-V curve represents the maximum loading of a system. The stability margin can be defined by the MW distant from the operating point to the critical point. The penetration of the DG units in a distributed system can increase or decrease the voltage stability margin depending on their operation at unity, lead or lag power factors [3].

\section{VOLTAGE STABILITY ANALYSIS}

The voltage stability analysis of the sensitivity is based on the flow equations, and uses the changes of some certain physical quantities to study the system stability. Voltage stability analysis has been presented by many techniques, including static and dynamic [3]. Voltage stability analysis is mainly conducted to predict the point of voltage collapse using the proposed fast voltage stability index (FVSI) and the relation between the receiving power $(\mathrm{P})$ and the voltage $(\mathrm{V})$ at a certain bus in the system which is known as P-V curve or nose curve. The P-V curve is obtained by applying a continuous power flow method [3]. It is performed on a distribution system in the Kumamoto area in Japan. The data for this system is provided in [25]

\section{SELECTION OF THE CANDIDATE BUSES}

The candidate buses for DG installation can be selected by calculating voltage stability indices. The candidate base has the highest number of voltage stability indices (sensitive base to the voltage stability). Because this study is focusing on improving the voltage stability of the system, it uses voltage sensitivity analysis to select the candidate buses. Additionally, the candidate buses should be located in the main feeders of the system. The method is conducted by testing the voltage sensitivity to the change of the DG injected power. Furthermore, the DG units are modeled as PQ buses, since they are not used to control the system voltage [26]. In this case, it can be used to study the impact of the DG units on voltage stability, voltage profile, power flow and P-V curve. The most sensitive buses should be selected as the candidate buses for the DG installation.

\section{DG PLACEMENT PROBLEM FORMULATION}

After the candidate buses are selected in Section IV, allocating DG units within the system requires study DG resources. In addition, placing the DG units in the most sensitive buses might violate the voltage limits or the capacity of the feeders, depending on the size of the DG units and the load demand of the system. Accordingly, this section proposes a method to place DG units with an objective of improving the voltage stability of the system. This study has demonstrated in three scenario`s.

Scenario \#1: is a reference scenario, in which no DG units are connected to the system (base case)

Scenario \#2: only wind-based DG units are connected.

Scenario \#3: only solar DG units are connected.

In this formulation, the following assumption is considered.

- All buses in the system are subjected to the same wind speed and solar irradiance. This assumption greatly simplifies the analysis.

\section{SYSTEM UNDER STUDY}

Figure 2 shows a single line diagram of a practical distribution system in the Kumamoto area in Japan. The system peak load 7.744 MVA and substation at bus 1 are used to feed the system with capacity 10 MVA. The load on the bus 11 is the largest in the system. The system's detailed line and load data can be found in [25]. The voltage at the substation is set to one p.u.

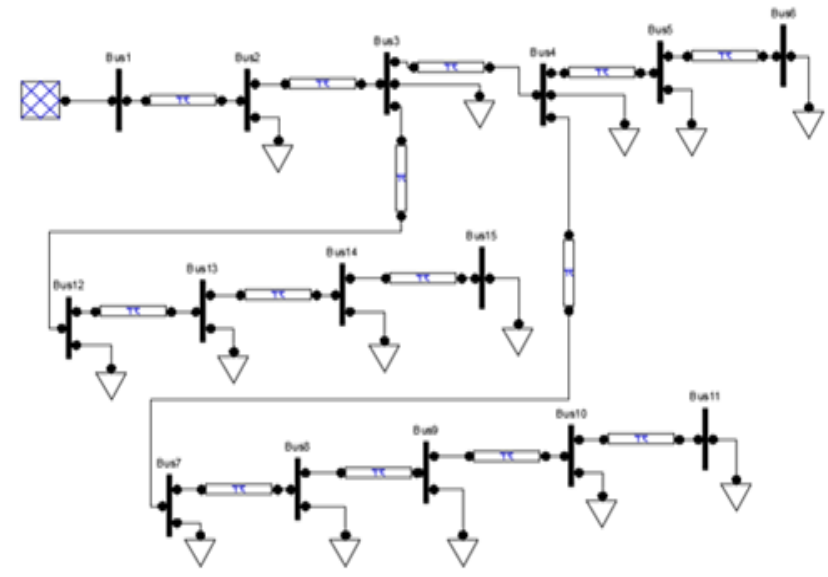

Fig 2: Practical radial distribution system in the Kumamoto area in Japan

\section{RESULTS}

This section outlines the results; they presented as follows: There are many types of DG. In this paper, two types of DG are interested. Two types are wind turbine \& photovoltaic.

\subsection{Wind Turbine}

It is worth mention that the installed DG unit is a wind turbine. Penetration level of wind turbine varied from 0 to $50 \%$ to show that the impact of increase penetration of wind turbine on voltage stability, voltage profile, power flow and the P-V curve at each bus.

$10 \%$ of the penetration level wind turbine means that the installed wind turbine generates real power equal 0.632361 MW \& reactive power equal 0.262383 MVAR. $20 \%$ of the penetration level wind turbine means that the installed wind turbine unit generates real power equal $1.264722 \mathrm{MW} \&$ reactive power equal $0.524766 \mathrm{MVAR} .30 \%$ of the penetration level wind turbine means that the installed wind turbine generates real power equal $1.897083 \mathrm{MW} \&$ reactive power equal 0.787149 MVAR.40\% of the penetration level wind turbine means that the installed wind turbine generates real power equal $2.529 \mathrm{MW} \&$ reactive power equal 1.04953 MVAR. $50 \%$ of the penetration level wind turbine means that the installed wind turbine generates real power equal 3.1618 MW \& reactive power equal 1.3119 MVAR. 


\subsubsection{Impact of Increased Penetration of wind turbine on voltage stability}

The candidate buses for the wind- turbine installation can be selected by selecting sensitive buses to voltage stability because this study is focusing on improving the voltage stability of the system.

According to the value of voltage stability indices without wind turbine in Table 1 it is found that bus 11 is the weakest bus. So the wind turbine is installed at bus 11 . The wind turbine unit varied from 0 to $50 \%$ penetration level to study the impacts of the increasing penetration level of wind turbine on the Voltage Stability Indices.
Table I represents values of fast voltage stability index (FVSI) at the different penetration level of the wind turbine.

From Tables 1 when installed wind turbine in bus 11 voltage stability improved at all buses. Also, when increases the penetration level of wind turbine, voltage stability more improved at all buses.

\subsubsection{Impact of Increased Penetration of wind} turbine on voltage profile

Table 2 shows the impact of wind turbine on voltage of each bus. From Table 2, the voltage of each bus improved when the wind turbine installed at the bus 11 . Furthermore, the voltage at each bus more improved when increases the penetration level of wind turbine generation.

Table 1. Value of FVSI with Different DG Size

\begin{tabular}{|c|r|r|r|r|r|r|}
\hline Line & $\begin{array}{c}\text { FVSI without } \\
\text { DG }\end{array}$ & $\begin{array}{c}\text { FVSI with } 10 \% \\
\text { DG }\end{array}$ & $\begin{array}{c}\text { FVSI with } 20 \% \\
\text { DG }\end{array}$ & $\begin{array}{c}\text { FVSI with } 30 \% \\
\text { DG }\end{array}$ & $\begin{array}{c}\text { FVSI with 40\% } \\
\text { DG }\end{array}$ & $\begin{array}{r}\text { FVSI with 50\% } \\
\text { DG }\end{array}$ \\
\hline 1 to 2 & 0.000632844 & 0.000632844 & 0.000632844 & 0.000632844 & 0.000632844 & 0.000632844 \\
\hline 2 to 3 & $4.05761 \mathrm{E}-05$ & $4.029 \mathrm{E}-05$ & $4.0029 \mathrm{E}-05$ & $3.97902 \mathrm{E}-05$ & $3.95715 \mathrm{E}-05$ & $3.9371 \mathrm{E}-05$ \\
\hline 3 to 4 & 0.001319688 & 0.001310118 & 0.001301386 & 0.001293398 & 0.001286079 & 0.001279365 \\
\hline 3 to 12 & 0.000777452 & 0.000771814 & 0.00076667 & 0.000761964 & 0.000757652 & 0.000753697 \\
\hline 4 to 5 & 0.000330131 & 0.000326591 & 0.000323359 & 0.000320398 & 0.000317678 & 0.000315174 \\
\hline 4 to 7 & 0.001090014 & 0.001078328 & 0.001067657 & 0.001057879 & 0.001048897 & 0.001040629 \\
\hline 5 to 6 & 0.000215397 & 0.000213085 & 0.000210975 & 0.000209041 & 0.000207265 & 0.00020563 \\
\hline 7 to 8 & 0.000628614 & 0.000619314 & 0.000610833 & 0.000603067 & 0.000595934 & 0.000589362 \\
\hline 8 to 9 & 0.000335212 & 0.000328733 & 0.00032284 & 0.000317454 & 0.000312513 & 0.000307963 \\
\hline 9 to 10 & 0.000236319 & 0.000230923 & 0.000226026 & 0.000221559 & 0.000217465 & 0.000213699 \\
\hline 10 to 11 & 0.044479556 & 0.043382597 & 0.042388353 & 0.040916513 & 0.040652352 & 0.039889339 \\
\hline 12 to 13 & 0.000117706 & 0.000116849 & 0.000116067 & 0.000115352 & 0.000114697 & 0.000114096 \\
\hline 13 to 14 & 0.000795375 & 0.000789567 & 0.000784269 & 0.000779422 & 0.000774982 & 0.000770909 \\
\hline 14 to 15 & 0.000391647 & 0.000388778 & 0.000386161 & 0.000383767 & 0.000381574 & 0.000379563 \\
\hline
\end{tabular}

Table 2. Value of Voltage at each Base with Different DG Size

\begin{tabular}{|l|l|l|l|l|l|l|}
\hline & Without DG & $10 \%$ DG & $20 \%$ DG & $30 \%$ DG & $40 \%$ DG & $50 \%$ DG \\
\hline Voltage at Bus 1 & 1 & 1 & 1 & 1 & 1 & \\
\hline Voltage at Bus 2 & 0.97939 & 0.98286 & 0.986064 & 0.989018 & 0.991748 & 0.99427 \\
\hline Voltage at Bus 3 & 0.97876 & 0.98233 & 0.985621 & 0.988659 & 0.991469 & 0.994067 \\
\hline Voltage at Bus 4 & 0.96805 & 0.97329 & 0.978142 & 0.982652 & 0.986851 & 0.990764 \\
\hline Voltage at Bus 5 & 0.96765 & 0.97289 & 0.977745 & 0.982257 & 0.986458 & 0.990372 \\
\hline Voltage at Bus 6 & 0.96744 & 0.97268 & 0.977536 & 0.982049 & 0.986251 & 0.990166 \\
\hline Voltage at Bus 7 & 0.95599 & 0.96314 & 0.969805 & 0.976028 & 0.981854 & 0.987313 \\
\hline Voltage at Bus 8 & 0.94282 & 0.95207 & 0.960719 & 0.968834 & 0.976465 & 0.983652 \\
\hline Voltage at Bus 9 & 0.93298 & 0.94382 & 0.953992 & 0.963562 & 0.972589 & 0.981122 \\
\hline Voltage at Bus 10 & 0.92793 & 0.93959 & 0.950553 & 0.960880 & 0.970638 & 0.979877 \\
\hline Voltage at Bus 11 & 0.91582 & 0.92946 & 0.942334 & 0.954508 & 0.966058 & 0.977039 \\
\hline Voltage at Bus 12 & 0.97680 & 0.98038 & 0.983681 & 0.986726 & 0.989541 & 0.992145 \\
\hline Voltage at Bus 13 & 0.97545 & 0.97903 & 0.982340 & 0.985389 & 0.988208 & 0.990815 \\
\hline Voltage at Bus 14 & 0.97391 & 0.97750 & 0.980807 & 0.983861 & 0.986685 & 0.989296 \\
\hline Voltage at Bus 15 & 0.97367 & 0.97726 & 0.980573 & 0.983628 & 0.986452 & 0.989064 \\
\hline
\end{tabular}




\subsubsection{Impact of Increased Penetration of wind} turbine on $P$-V curves for distribution system

The P-V curves are the most used to determine the loading margin of a power system at an individual load bus. To build P-V curves, at a base

case, the power system load is gradually increased. For each incremental load, it is necessary to recalculate power flows so that the bus voltage corresponding to the load is determined the increment of load is stopped when the voltage collapse point of the nose of the $\mathrm{P}-\mathrm{V}$ curve is reached. Figure 4 shows the $\mathrm{P}-\mathrm{V}$ curves at all buses of the feeder without wind turbine.

The figure shows that the weakest bus is the bus 11 which is physically located at the far end of the radial feeder. This is certain that the best location of wind turbine at bus 11. Figure 3, $4,5,6,7 \& 8$ shows the impact of increase the penetration level of wind turbine on P-V curve of each bus.

Table 3 shows the impact of increase the penetration level of DG on the maximum value of the loading parameter of the distribution system. The maximum value of the loading parameter of the system increased when increases the penetration level of wind turbine.

Table 3. The Impact of Increasing Size of DG on Max Loadability

\begin{tabular}{|c|c|}
\hline DG & Max. Loadability \\
\hline $0 \%$ & 2.6291 \\
\hline $10 \%$ & 2.7857 \\
\hline $20 \%$ & 2.9134 \\
\hline $30 \%$ & 3.0195 \\
\hline $40 \%$ & 3.1058 \\
\hline $50 \%$ & 3.1477 \\
\hline
\end{tabular}

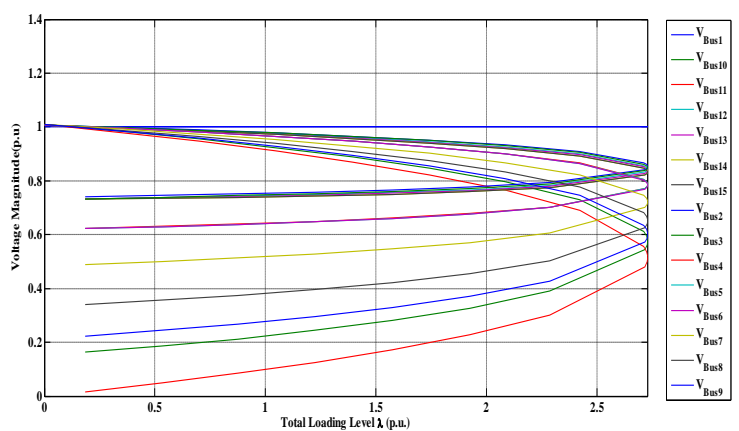

Fig 3: P-V Curves without DG

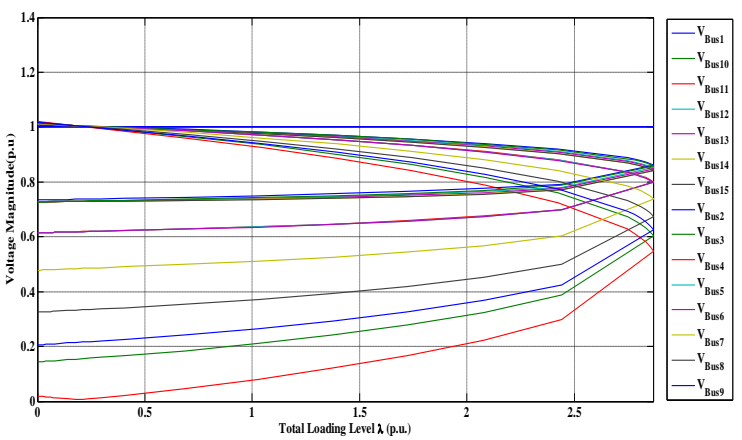

Fig 4: P-V Curves with 10\% penetration of DG

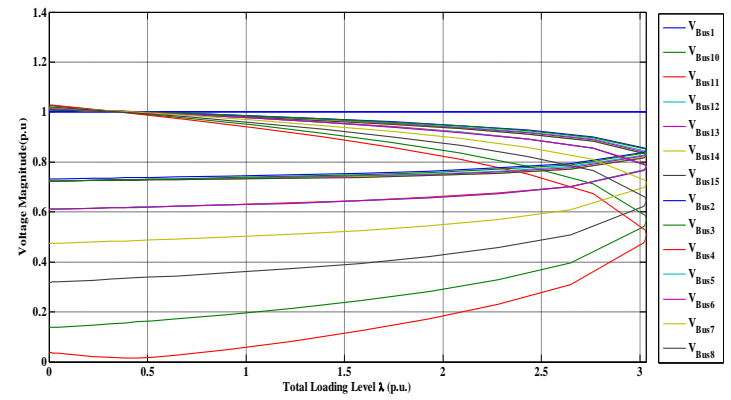

Fig 5: P-V Curves with $20 \%$ penetration of DG

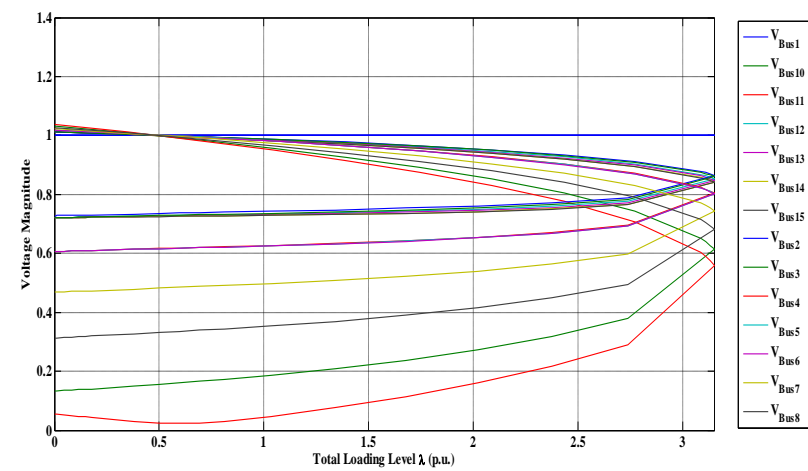

Fig 6: P-V Curves with 30\% penetration of DG

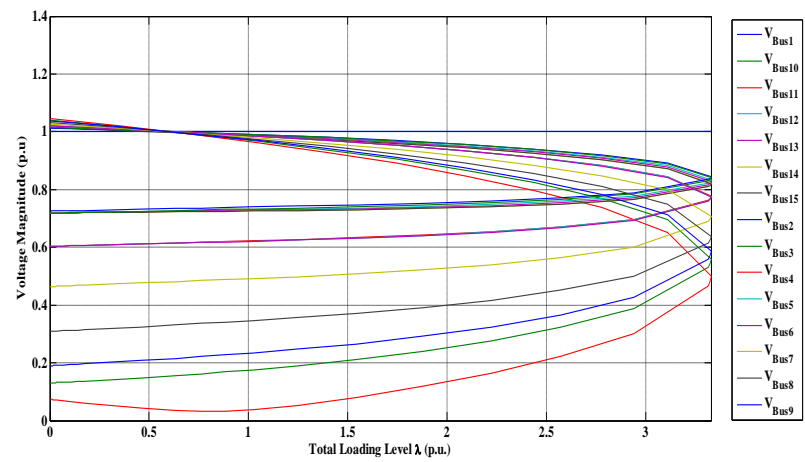

Fig 7: P-V Curves with $40 \%$ penetration of DG

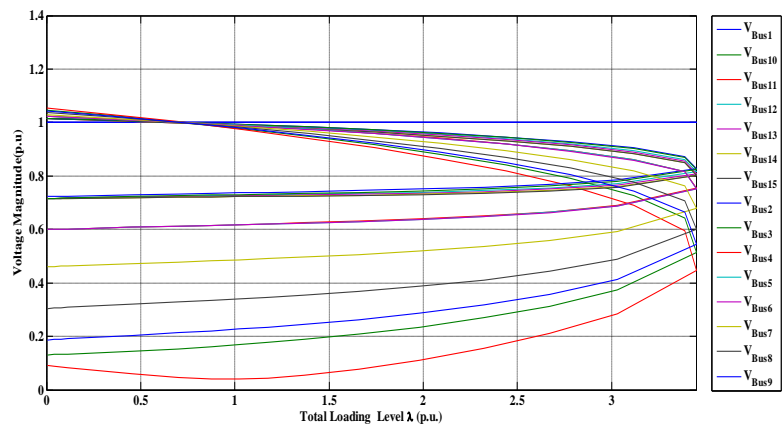

Fig 8: P-V Curves with $50 \%$ penetration of DG

\subsection{Photovoltaic}

It is worth mention that the installed DG unit is a photovoltaic. Penetration level of photovoltaic varied from 0 to 50 to show the impact of increase penetration of photovoltaic on voltage stability, voltage profile, power flow \& P-V curve at each bus. 
$10 \%$ of penetration level photovoltaic means that the installed photovoltaic generates real power equal 0.632361 MW. $20 \%$ of penetration level photovoltaic means that the installed photovoltaic generates real power equal $1.264722 \mathrm{MW} .30 \%$ of penetration level photovoltaic means that the installed photovoltaic generates real power equal $1.897 \mathrm{MW} .40 \%$ of penetration level photovoltaic means that the installed photovoltaic generates real power equal 2.529 MW. $50 \%$ of penetration level photovoltaic means that the installed photovoltaic generates real power equal 3.1618 MW.

\subsubsection{Impact of Increased Penetration of}

Photovoltaic Generation on Voltage Stability

The candidate buses for the DG installation can be selected by selecting sensitive buses to voltage stability because this study is focusing on improving the voltage stability of the system.

According to the values of voltage stability index without photovoltaic in Table 5 it is found that bus 11 is the weakest bus.
So the photovoltaic is installed at bus 11 . The photovoltaic is varied from 0 to $50 \%$ penetration level to study the impacts of the photovoltaic on Voltage Stability Indices.

Table 4 represents values of fast voltage stability index (FVSI) at different photovoltaic size.

From table 4 when installed photovoltaic in bus 11 Voltage stability improved at all buses. Also, when increases penetration level of photovoltaic, voltage stability more improved at all buses.

\subsubsection{Impact of Increased Penetration of} Photovoltaic Generation on Voltage Profile

Table 5 shows the impact of photovoltaic on voltage of each bus. From Table 5, the voltage at each bus improved when photovoltaic installed at bus 11 .

Also, when increases the penetration level of photovoltaic generation the voltage at each bus more improved.

Table 4. Value of FVSI with Different DG Size

\begin{tabular}{|c|c|c|c|c|c|c|}
\hline Line & $\begin{array}{c}\text { FVSI without } \\
\text { DG }\end{array}$ & $\begin{array}{c}\text { FVSI with 10\% } \\
\text { DG }\end{array}$ & $\begin{array}{c}\text { FVSI with 20\% } \\
\text { DG }\end{array}$ & $\begin{array}{c}\text { FVSI with 30\% } \\
\text { DG }\end{array}$ & $\begin{array}{c}\text { FVSI with 40\% } \\
\text { DG }\end{array}$ & $\begin{array}{c}\text { FVSI with 50\% } \\
\text { DG }\end{array}$ \\
\hline 1 to 2 & 0.000632844 & 0.000632844 & 0.000632844 & 0.000632844 & 0.000632844 & 0.000632844 \\
\hline 2 to 3 & $4.05761 \mathrm{E}-05$ & $4.04811 \mathrm{E}-05$ & $4.04025 \mathrm{E}-05$ & $4.03397 \mathrm{E}-05$ & $4.02919 \mathrm{E}-05$ & $4.02586 \mathrm{E}-05$ \\
\hline 3 to 4 & 0.001319688 & 0.001316489 & 0.00131384 & 0.001311712 & 0.001310084 & 0.001308939 \\
\hline 3 to 12 & 0.000777452 & 0.000775568 & 0.000774007 & 0.000772753 & 0.000771794 & 0.000771119 \\
\hline 4 to 5 & 0.000330131 & 0.000328844 & 0.000327745 & 0.000326825 & 0.000326075 & 0.000325487 \\
\hline 4 to 7 & 0.001090014 & 0.001085764 & 0.001082138 & 0.0010791 & 0.001076622 & 0.001074682 \\
\hline 5 to 6 & 0.000215397 & 0.000214556 & 0.000213839 & 0.000213238 & 0.000212748 & 0.000212364 \\
\hline 7 to 8 & 0.000628614 & 0.000625118 & 0.000622087 & 0.000619494 & 0.000617313 & 0.000615527 \\
\hline 8 to 9 & 0.000335212 & 0.000332749 & 0.000330592 & 0.000328717 & 0.00032711 & 0.000325754 \\
\hline 9 to 10 & 0.000236319 & 0.000234267 & 0.000232457 & 0.00023087 & 0.000229491 & 0.000228309 \\
\hline 10 to 11 & 0.044479556 & 0.044062968 & 0.043694107 & 0.04336928 & 0.04308547 & 0.042840216 \\
\hline 12 to 13 & 0.000117706 & 0.00011742 & 0.000117183 & 0.000116992 & 0.000116846 & 0.000116744 \\
\hline 13 to 14 & 0.000795375 & 0.000793433 & 0.000791825 & 0.000790534 & 0.000789546 & 0.000788851 \\
\hline 14 to 15 & 0.000391647 & 0.000390688 & 0.000389893 & 0.000389256 & 0.000388768 & 0.000388424 \\
\hline
\end{tabular}

Table 5. Value of Voltage at each Base with Different DG Size

\begin{tabular}{|c|c|c|c|c|c|c|}
\hline & Without DG & $10 \% \mathrm{DG}$ & $20 \% \mathrm{DG}$ & $30 \% \mathrm{DG}$ & $40 \% \mathrm{DG}$ & $50 \% \mathrm{DG}$ \\
\hline Voltage at Bus 1 & 1 & 1 & 1 & 1 & 1 & 1 \\
\hline Voltage at Bus 2 & 0.97939 & 0.98054 & 0.98149 & 0.9822 & 0.9828 & 0.9832 \\
\hline Voltage at Bus 3 & 0.97876 & 0.97995 & 0.98093 & 0.9817 & 0.9823 & 0.9827 \\
\hline Voltage at Bus 4 & 0.96805 & 0.96995 & 0.97157 & 0.9729 & 0.9740 & 0.9749 \\
\hline Voltage at Bus 5 & 0.96765 & 0.96955 & 0.97117 & 0.9725 & 0.9736 & 0.9745 \\
\hline Voltage at Bus 6 & 0.96744 & 0.96934 & 0.97096 & 0.9723 & 0.9734 & 0.9743 \\
\hline Voltage at Bus 7 & 0.95599 & 0.95866 & 0.96099 & 0.9630 & 0.9647 & 0.9661 \\
\hline Voltage at Bus 8 & 0.94282 & 0.94630 & 0.94938 & 0.9520 & 0.9544 & 0.9564 \\
\hline Voltage at Bus 9 & 0.93298 & 0.93706 & 0.94070 & 0.9439 & 0.9467 & 0.9492 \\
\hline Voltage at Bus 10 & 0.92793 & 0.93231 & 0.93624 & 0.9397 & 0.9428 & 0.9455 \\
\hline Voltage at Bus 11 & 0.91582 & 0.92090 & 0.92551 & 0.9296 & 0.9334 & 0.9367 \\
\hline Voltage at Bus 12 & 0.97680 & 0.97799 & 0.97898 & 0.9797 & 0.9803 & 0.9808 \\
\hline
\end{tabular}




\begin{tabular}{|c|l|l|l|l|l|l|}
\hline Voltage at Bus 13 & 0.97545 & 0.97665 & 0.97764 & 0.9784 & 0.9790 & 0.9794 \\
\hline Voltage at Bus 14 & 0.97391 & 0.97510 & 0.97610 & 0.9769 & 0.9775 & 0.9779 \\
\hline Voltage at Bus 15 & 0.97367 & 0.97487 & 0.97586 & 0.9766 & 0.9772 & 0.9777 \\
\hline
\end{tabular}

\subsubsection{Impact of Increased Penetration of photovoltaic generation on $P-V$ curves for distribution system}

The P-V curves are the most used to determine the loading margin of a power system at an individual load bus. To build $\mathrm{P}-\mathrm{V}$ curves, at a base case, the power system load is gradually increased. For each incremental load, it is necessary to recalculate power flows so that the bus voltage corresponding to the load is determined the increment of load is stopped when the voltage collapse point of the nose of the P-V curve is reached.

Figure 9 shows the $\mathrm{P}-\mathrm{V}$ curves at all buses of the feeder without photovoltaic. Fig.11 shows that the weakest bus is the bus 11 which is physically located at the far end of the radial feeder. Now consider that the Distributed generation was installed at this bus 11. This is certain that the best location of photovoltaic at bus 11 . Figures 9, 10, 11, 12, 13 \& 14 show the impact of increase penetration level of photovoltaic on P-V curve of each bus.

Table 6 shows the impact of increase penetration level of photovoltaic on the maximum value of the loading parameter of the distribution system. The maximum value of the loading parameter of system, increase when increase penetration level of installed photovoltaic but when reach penetration level to a certain level, maximum value of the loading parameter decrease. From result analysis, optimum penetration level is needed to reach the best maximum value of the loading parameter of the system.

Table 6. The Impact of Increasing Size of DG on Max Loadability

\begin{tabular}{|l|l|}
\hline DG & Max. Loadability \\
\hline $0 \%$ & 2.6291 \\
\hline $10 \%$ & 2.724 \\
\hline $20 \%$ & 2.7867 \\
\hline $30 \%$ & 2.8218 \\
\hline $40 \%$ & 2.8271 \\
\hline $50 \%$ & 2.8011 \\
\hline
\end{tabular}

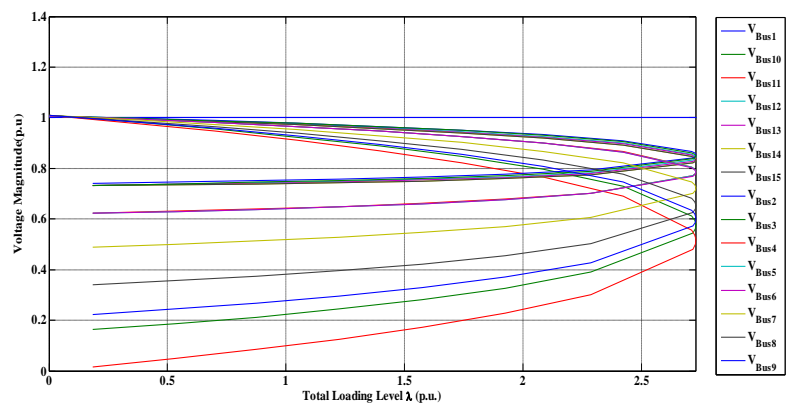

Fig 9: P-V Curves without DG

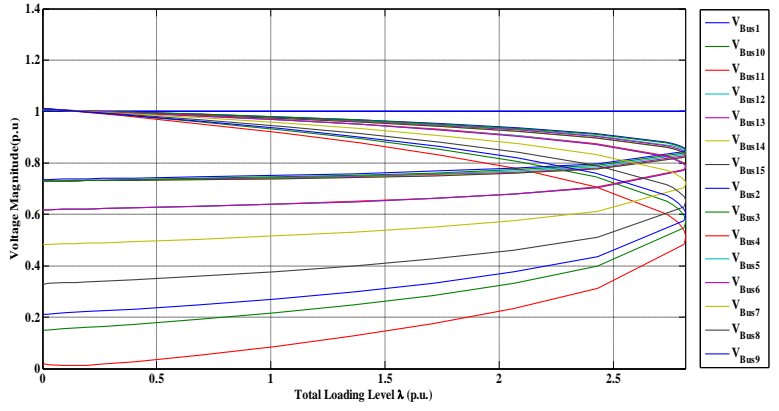

Fig 10: P-V Curves with $10 \%$ penetration of DG

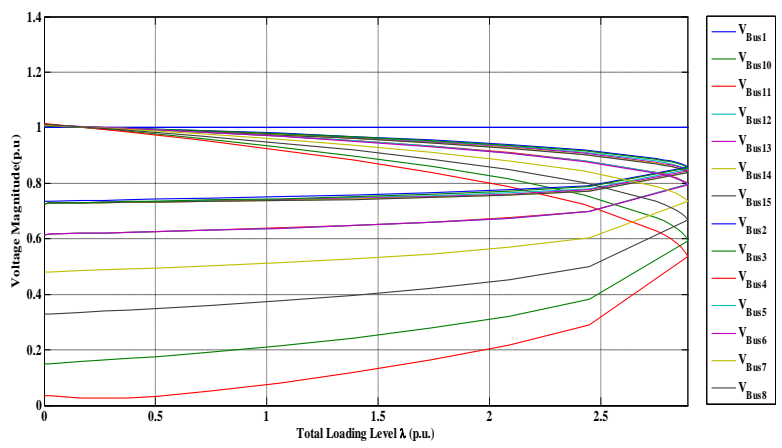

Fig 11: P-V Curves with 20\% penetration of DG
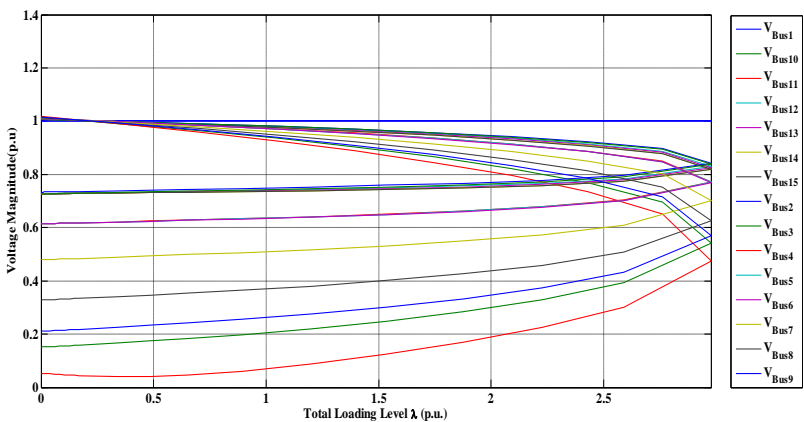

Fig 12: P-V Curves with $30 \%$ penetration of DG

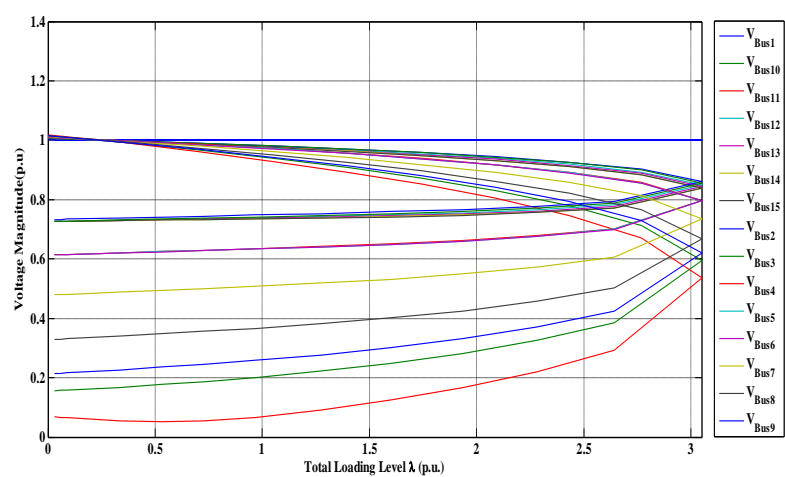

Fig 13: P-V Curves with $40 \%$ penetration of DG 


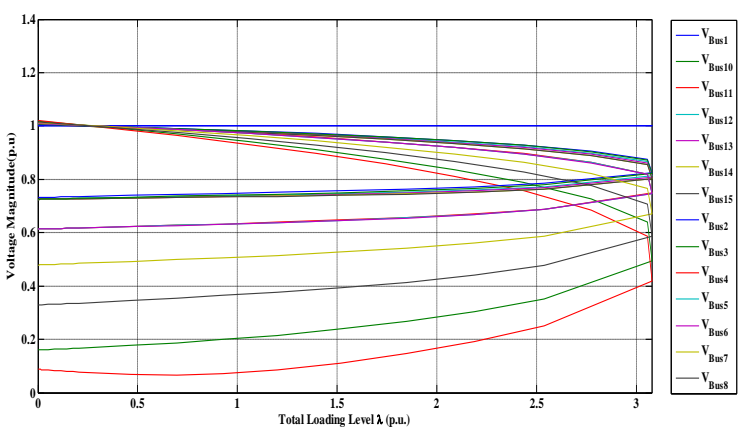

Fig 14: P-V Curves with $50 \%$ penetration of DG

\section{COMPARISON BETWEEN WIND TURBINE DG \& PHOTOVOLTAIC DG}

This section outlines the comparison between wind turbine DG \& photovoltaic DG by voltage stability, voltage profile, power flow and max value of a loading parameter of the system.

\subsection{Voltage Stability}

From tables $1 \& 5$, the weakest bus is bus 11 . So the comparison between wind turbine DG \& Photovoltaic DG by calculating voltage stability index the weakest bus (bus 11).

Figure 15 shows the impact of the penetration level of wind turbine DG \& Photovoltaic DG on the voltage stability index in bus 11. Fig. 17 shows that the voltage stability index improved in the case of the installation wind Turbine DG better than the installation photovoltaic DG.

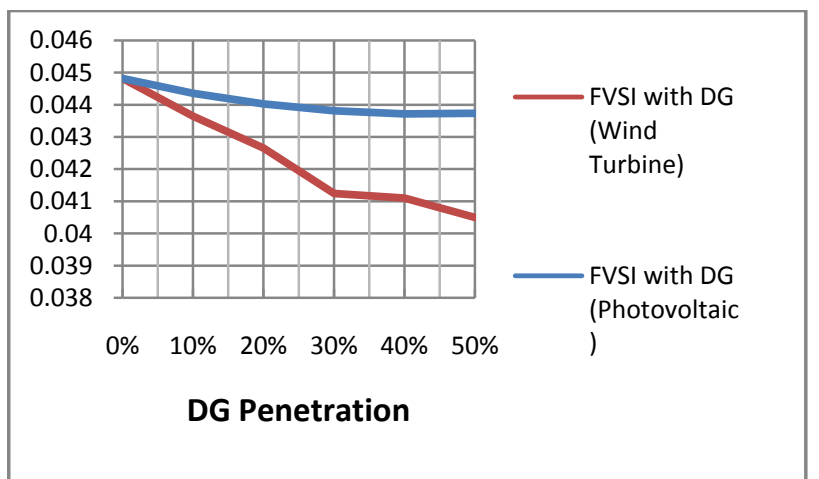

Fig 15: The impact of wind turbine \& photovoltaic on voltage stability

\subsection{Voltage Profile}

From tables $1 \& 5$, the weakest bus is bus 11 . So, the compare between wind turbine DG \& Photovoltaic DG by calculating voltage profile at the weakest bus (bus 11). Figure 18 shows the impact of the penetration level of wind turbine DG \& Photovoltaic DG on the voltage profile in bus 11. Figure 16 shows that the voltage profile improved in the case of the installation wind turbine better than the installation photovoltaic.

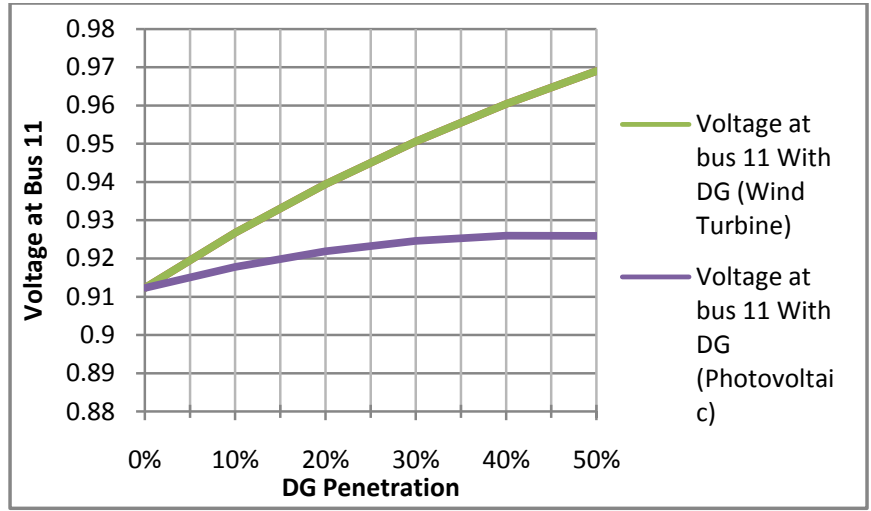

Fig 16: The impact of wind turbine \& photovoltaic on Voltage profile at bus 11

\subsection{P-V Curve}

Figure 21 shows the impact of the penetration level of wind turbine DG \& Photovoltaic DG on max loading point. Figure 17 shows that max loading point in the case of the installation wind Turbine greater than in the case of the installation photovoltaic. When reach a certain level in the case of photovoltaic DG max loading point decrease.

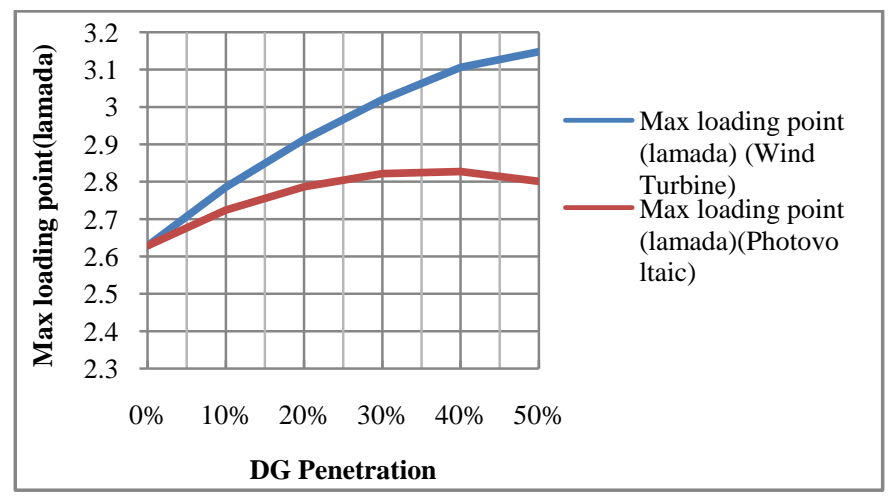

Fig 17: The impact of wind turbine \& photovoltaic on max loading point

\section{CONCLUSION}

In this paper, a method of DG unit allocation is proposed. This method targets to utilize the DG units to improve the voltage stability margin. This research work focuses on analyzing voltage stability, voltage profile, power flow and the P-V curve of a system with integrate wind turbine or photovoltaic in the distribution system. The candidate buses for the DG units' installation are selected based on the sensitivity to the voltage stability. Simulation results indicate that DG size and location can have a positive impact on the voltage stability margin. Therefore, an optimization method can be used to design the locations and sizes of the DG units, to achieve the target of improving the voltage stability margin. The simulation results indicate the highest penetration level of the wind turbine units are recommended to be placed in the most sensitive voltage buses in order to improve the voltage stability margin. The simulation results indicate optimum penetration level of the photovoltaic are recommended to be placed in the most sensitive voltage buses in order to improve the voltage stability margin. 


\section{REFERENCES}

[1] R.M. Dell and D.A.J. Rand, "Energy storage-A key technology for global energy sustainability," J. Power Sources, vol. 100, issues 1-2, pp. 2-17, Nov. 2001.

[2] Y. M. Atwa and E. F. El-Saadany, "Optimal Allocation of ESS in Distribution Systems with a High Penetration of Wind Energy," IEEE Trans. Power Syst., vol.25, no.4, pp.1815-1822, Nov. 2010

[3] R. S. Al Abri, E. F. El-Saadany and Y. M. Atwa,"Distributed Generation Placement and Sizing Method to Improve the Voltage Stability Margin in a Distribution System"IEEE Electric Power and Energy Conversion Systems (EPECS), Sharjah, 2011.

[4] Pathomthat Chiradeja, R.Ramakumar, "An Approach to Quantify the Technical Benefits of Distributed Generation", IEEE Transactions on Energy Conversion, Vol.19, No.4, December 2004.

[5] Pathomthat Chiradeja, R.Ramakumar, "An Approach to Quantify the Technical Benefits of Distributed Generation", IEEE Transactions on Energy Conversion, Vol.19, No.4, December 2004.

[6] J. M. Sexauer, and S. Mohagheghi, "Voltage quality assessment in a distribution system with distributed generation-a probabilistic load flow approach," IEEE Trans. Power Del., vol. 28, no. 3, pp. 1653- 1662, Jul. 2013

[7] S. Eftekharnejad, V. Vittal, G. T. Heydt, B. Keel, and J. Loehr, "Impact of increased penetration of photovoltaic generation on power systems," IEEE Trans. Power Syst., vol. 28, no. 2, pp. 893-901, May 2013.

[8] E. Naderi, H. Seifi, and M. S. Sepasian, "A dynamic approach for distribution system planning considering distributed generation," IEEE Trans. Power Del., vol. 27, no. 3, pp. 1313-1322, Jul. 2012.

[9] Haiyan Chen, Jinfu Chen, Dongyuan Shi, Xianzhong Duan, Member, IEEE, "Power Flow Study and Voltage Stability Analysis for Distribution Systems with Distributed Generation",IEEE,2006, 1-4244-0493.

[10] "Voltage Stability of Power Systems: Concepts, Analytical Tools and Industry Experience", IEEE Committee Vol.IEEE/PES 93TH0358-2- PWR 1990.

[11] K. Takahashi and Y. Nomura "The Power System Failure on July 23rd 1987 in Tokyo" CIGRE SC-37 Meeting 37.87(JP)07(E) 1987.

[12] Prada, R.B.; Souza, L.J.; "Voltage stability and thermal limit: constraints on the maximum loading of electrical energy distribution feeders", IEE ProceedingsGeneration, Transmission and Distribution, Volume 145, Issue 5, Sept. 1998 Page(s): 573 - 577.
[13] Liu Daowei, Xie Xiaorong, Mu Gang, "An on-line voltage stability index of power system based on synchronized phasor measurement", Proceedings of the CSEE, 2005, 25(1): 13-17.

[14] Haiyan Chen, Jinfu Chen, Dongyuan Shi, Xianzhong Duan, Member, IEEE, "Power Flow Study and Voltage Stability Analysis for Distribution Systems with Distributed Generation",IEEE,2006, 1-4244-0493.

[15] P.Kundur "Power System Stability and Control" McGraw-Hill, New York, 1994.

[16] G.K.Morison, B.Gao and P.Kundur, "Voltage Stability Analysis Using Static and Dynamic Approaches", IEEE Trans. Vol.PS-8, No.2, August 1993.

[17] R. S. Al Abri, E. F. El-Saadany, and Y. M. Atwa "Optimal placement and sizing method to improve the voltage stability margin in a distribution system using distributed generation," IEEE Trans. Power Syst., vol. 28, no. 1, pp. 326-334, Feb. 2013

[18] M. D. McDonald, R. A. Walling, R. D'Aquila, and J.G. Cleary, "Effect of distributed generation on regional voltage stability," in Proc. IEEE Power Eng. Soc. Trans. Distrib. Conf., Orlando, United States, May 2012, pp. 16.

[19] A. B. Rodrigues, R. B. Prada, and M. D. G. Da Silva, "Voltage stability probabilistic assessment in composite systems: modeling unsolvability and controllability loss," IEEE Trans. Power Syst., vol. 25, no. 3, pp. 15751588, Aug. 2010.

[20] P. C. Loh, D. Li, Y. K. Chai, and F. Blaabjerg, "Hybrid AC-DC microgrids with energy storages and progressive energy flow tuning," IEEE Trans. Power Electron., vol. 28, no. 4, pp. 1533-1543, Apr. 2013.

[21] Claudia Reis, F.P. Maciel Barbosa "” A Comparison of Voltage Stability Indices" IEEE MELECON 2006, May 16-19, Benalmádena (Málaga), Spain.

[22] I.Musirin, T.K.A.Rahman "Novel Fast Voltage Stability Index (FVSI) for Voltage Stability Analysis in Power Transmission System" 2002 Student Conference on Research and Development Proceedings, Shah Alam, Malasia, July 2002.

[23] Claudio Canizares "Voltage Stability Assessment Concepts, Practices and Tools" IEEE/PES Power System Stability Subcommittee Special Publication, August 2002.

[24] C. A. Canizares and F. L. Alvarado, "Point of collapse and continuation methods for large AC/DC systems," IEEE Trans. Power Syst., vol. 8, pp. 1-8, 1993.

[25] S. Li K. Tomsovic ,T. Hiyama"Load Following Functions Using Distributed Energy Rtsources"0-78036420-2000 IEEE 